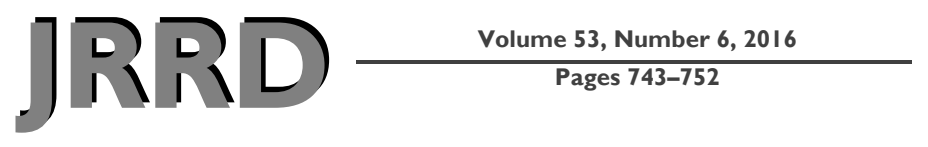

\title{
Relationship between symptoms and family relationships in Veterans with serious mental illness
}

\author{
Morgan Haselden, BA; ${ }^{1}$ Sarah Piscitelli, MA; ${ }^{1}$ Amy Drapalski, PhD; ${ }^{2}$ Deborah Medoff, PhD; ${ }^{3}$ Shirley M. \\ Glynn, PhD; ${ }^{4}$ Amy N. Cohen, PhD; ${ }^{4-5}$ Lisa B. Dixon, MD, MPH ${ }^{1,6 *}$ \\ ${ }^{1}$ New York State Psychiatric Institute, New York, NY; ${ }^{2}$ Department of Veterans Affairs (VA) Capitol Health Care Network \\ (Veterans Integrated Service Network [VISN] 5) Mental Illness Research, Education, and Clinical Center (MIRECC), Bal- \\ timore, MD; ${ }^{3}$ Department of Psychiatry, University of Maryland School of Medicine, Baltimore, MD; ${ }^{4}$ A Desert Pacific \\ Healthcare Network (VISN 22) MIRECC, Los Angeles, CA; ${ }^{5}$ Department of Psychiatry and Biobehavioral Sciences, Uni- \\ versity of California, Los Angeles, CA; ${ }^{6}$ Department of Psychiatry, Columbia University Medical Center, New York, NY
}

\begin{abstract}
Little is known about how the symptoms experienced by individuals with serious mental illness (SMI) affect family relationships. This study assessed the association between symptoms and patient perceptions of family relationships. The sample of 226 outpatient Veterans diagnosed with SMI, whose relatives had low contact rates with treatment staff, was enrolled in a study that used shared decision making to consider family involvement in care. We analyzed baseline data using multiple regressions to understand the unique effect that positive, negative, and depressive symptoms have on perceptions of family relationships, including general functioning, problem solving, communication, support, satisfaction, conflict, and distress. Greater depressive and disorganized symptoms were significant, unique predictors of perceptions of poorer communication and problem solving, while higher levels of expressive negative symptoms - blunted affect, lack of spontaneity, and motor retardation-were unique predictors of better communication and problem solving. More depressive symptoms also significantly predicted perceptions of greater family conflict and distress. While we cannot assume causation, these associations underscore the important role of depression and expressive negative symptoms in adopting a family-centered approach in the care of persons with SMI.
\end{abstract}

Clinical Trial Registration: ClinicalTrials.gov: "The effectiveness of FMPO in improving the quality of care for persons with severe mental illness"; NCT00466323; https://clinicaltrials.gov/ct2/show/NCT00466323
Key words: communication, conflict, depression, family, functioning, negative symptoms, patient perceptions, psychosis, serious mental illness, symptom predictors.

\section{INTRODUCTION}

Research consistently shows that family involvement in the care of adults with serious mental illness (SMI) is associated with better outcomes, including reductions in clinical symptoms and relapse rates and improved treatment adherence and consumer functioning [1-5]. Previous research also shows that, in spite of this evidence, few family members of adults have contact with their relatives'

\footnotetext{
Abbreviations: FAD = Family Assessment Device; FCD = Family Conflict and Distress; FPSC $=$ Family Problem Solving Communication; MIRECC = Mental Illness Research, Education, and Clinical Center; PANSS = Positive and Negative Syndrome Scale; PFSS = Perceived Family Support and Satisfaction; REORDER = Recovery-Oriented Decisions for Relative's Support; SMI = serious mental illness; VA = Department of Veterans Affairs.

*Address all correspondence to Lisa B. Dixon, MD, MPH; New York State Psychiatric Institute, 1051 Riverside Dr, Box 100, Room 2702, New York, NY 10032; 646-774-8420; fax: 646-774-8421. Email: Dixonli@nyspi.columbia.edu http://dx.doi.org/10.1682/JRRD.2015.08.0158
} 
treatment teams, in part because of barriers at the family and consumer level that may inhibit family involvement [6-7]. Greater understanding of how patients' symptoms influence their family relationships and vice versa could guide strategies to promote family involvement in care and help clinicians provide more effective support to patients and families.

Previous studies on the association between patient symptoms and family relationships have focused on individuals diagnosed with depression; findings suggest that greater depression severity and poorer recovery correlate with lower patient-perceived family functioning and supports [8-10]. A cross-sectional study by Febres et al. found that among 117 inpatients diagnosed with severe depression, worse depression was correlated with poorer patientreported family functioning as measured by the Family Assessment Device (FAD) [8]. Longitudinal research shows similar results [9-10]. Kamen et al. interviewed 373 depressed patients at baseline and after 1, 4, 10, and $23 \mathrm{yr}$ [9]. Fewer depressive symptoms were associated with greater perceived family support at baseline and all subsequent time points, as well as with more rapid recovery trajectories over time. Keitner et al. assessed 78 depressed patients at hospital discharge and at 6 and 12 mo follow-up [10]. Nonrecovery or worse depression was associated with poorer patient-perceived family functioning (measured by the FAD) at all time points [10]. A cross-sectional study by Lincoln et al. examined the relationship between psychiatric symptoms and patient perception of family support in racially diverse populations with consistent findings [11]. The study surveyed 591 African Americans and measured depressive symptoms, family support, financial strain, and traumatic events. Fewer depressive symptoms were associated with greater levels of perceived family support [11].

Among individuals with psychotic disorders, research has examined the relationship between psychotic symptoms and patient perception of caregiver criticism. Onwumere et al. interviewed 67 patients who had experienced psychosis and had a recent psychotic relapse [12]. An analysis of baseline data showed a significant positive correlation between perceived criticism and scores on the general subscale of the Positive and Negative Syndrome Scale (PANSS). Tomlinson et al. conducted a cross-sectional study of 33 adult patients with early psychosis and 24 firstdegree relatives (all parents) [13]. Results showed that patient perception of higher caregiver criticism, measured by the Family Attitudes Scale, was strongly correlated with greater psychotic symptoms (measured by the Brief Psychiatric Rating Scale) and higher levels of anxiety and depression (measured by the Hospital Anxiety and Depression Scale) [13].

To our knowledge, no studies have examined the relationship between both depressive and psychotic symptoms and patient perceptions of multiple domains of their family relationships, including family functioning, problem solving, communication, conflict, distress, relationship support, and satisfaction among a broad sample of participants, including many diagnosed with psychotic disorders. Additionally, previous literature has focused on the effect of family support, or lack thereof, on patient symptoms [8-13]. This study explores how patient symptoms uniquely affect patients' perceptions of their family relationships. A deeper understanding of how these symptoms interact with patients' perceptions of family relationships could inform new intervention strategies for individuals with SMI that aim to improve patient outcomes by improving family support and enhancing family involvement in care.

This study was a secondary analysis of a randomized trial that tested the Recovery-Oriented Decisions for Relative's Support (REORDER) intervention-an innovative, manualized protocol that uses a shared decision-making process to consider family involvement in care [14-16]. The REORDER study sample included 226 Veterans with SMI whose relatives had low rates of contact with treatment staff at study entry. For this study, we examined the relationship between symptoms and patient perceptions of family relationships at baseline. We hypothesized that more severe depressive and psychotic symptomology would correlate with less positive perceptions of family relationships.

\section{METHODS}

\section{Description of Participants and Procedures}

Study participants included both consenting Veterans who had received SMI diagnoses and, with the Veterans' permission, at least one consenting relative of each Veteran [15]. Recruitment sites included outpatient mental health programs situated at three medical centers within two Veterans Integrated Service Networks. Potential participants were identified via three routes: clinician referrals, a systematic review of clinical and program rosters, and recruitment materials displayed in participating clinics. Individuals were 
eligible if they were between the ages of 18 and $75 \mathrm{yr}$; had a chart diagnosis of schizoaffective disorder, schizophrenia, major depression with psychotic features, bipolar disorder (any type), or psychotic disorder not otherwise specified; and had a minimum of two outpatient mental health visits and contact with a caregiver or family member within the past 6 mo. Exclusion criteria included a history of homelessness, a significant traumatic brain injury, or having a relative who was frequently in contact with the clinical team (e.g., contact with a clinician at least monthly in the past $6 \mathrm{mo}$ ). Individuals needed to be willing to discuss possible family involvement in care; they were not required to commit to family inclusion in care [15].

Eligible individuals were approached either in person at clinic appointments or by letter (at two of three sites). Letters notified the individual of potential eligibility and requested the individual contact study staff directly or return a postcard that permitted study staff to directly contact the individual. Upon contact, study staff described the study and, when applicable, met with the individual to obtain written informed consent. The institutional review boards of the University of Maryland School of Medicine and the Department of Veterans Affairs (VA) Greater Los Angeles Healthcare System approved the study [15].

Of the 345 eligible consumers approached, 232 $(67 \%)$ provided written informed consent. A total of 226 participants completed an initial in-person 90 min interview conducted by a research staff member. For the main study, individuals were assigned to REORDER or enhanced treatment as usual; however, because only baseline data were considered for this article, treatment assignment was not relevant [15].

\section{Assessments and Variables}

Baseline assessments collected demographics, symptoms, and self-reports of family and caregiver relationships.

\section{Symptoms}

Symptoms were assessed with the PANSS [17]. The PANSS is an interviewer-administered severity measure that targets symptoms associated with schizophrenia (based on severity within the past week). It includes 30 items rated on a 7-point scale, from $1=$ absent to $7=$ extreme severity. Research assistants received biweekly supervision on the PANSS to ensure reliability. While the PANSS was initially scored with three subscales (positive, negative, and general symptoms) [17], over time researchers have proposed a number of PANSS structural models to more precisely measure symptom dimensions of schizophrenia [18]. Wallwork et al.'s [19] PANSS five-factor model includes five subscales (positive, negative, disorganized, excited, and depressive) whose psychometric properties have been demonstrated to be good and have been validated in multiple samples [18-19]. This five-factor model has guided our creation of the PANSS scale scores used in this analysis [19]. Further, based on accumulating evidence [20-21] that negative symptoms are not unidimensional and are best represented by two facets - expression, which captures emotion, expression, and speech; and motivation and pleasure, which captures motivation and pleasure for engaging in social, vocational, and recreational activities - we divided the negative symptom items from Wallwork et al. [19] to create two separate negative symptom scores that reflect motivation and pleasure and expressive negative symptoms. It is important to note that "expressive negative symptoms" differ from "expressed negative affect," which would reflect more anger and irritation.

\section{Family Problem Solving, General Functioning, and Communication}

We used the FAD and the Family Problem Solving Communication (FPSC) scale to measure patient perceptions of family relationships, including dimensions of family functioning, problem solving, and communication. The FAD is an evaluative measure of family relations and family functioning and has well-established validity and reliability [22]. Although the FAD is composed of seven subscales, the original REORDER study chose to include just two subscales - problem solving ( 6 items) and general functioning (12 items), which were derived from Measures for Clinical Practice and Research [23]. We used the problem solving and general functioning subscales to assess family response to illness. The FPSC is a 10-item index that measures negative and positive facets of communication within families, including both incendiary and affirming communication, as well as overall problem solving (FPSC Total) [24].

\section{Perceived Family Support and Satisfaction}

The Perceived Family Support and Satisfaction (PFSS) is a two-factor subscale of the Family Stability Index [25], originally used in a National Alliance on Mental Illness consumer survey and further used in the Patient Outcomes Research Team study to assess consumers' empowerment within the family and consumers' perceived support. Family empowerment is measured with items such as "You have 
influence in your family" and "You feel your opinions and ideas count in your family," and examples of perceived support are "You feel your family accepts you the way you are" and "You feel you can depend on family members when you need help" [26]. Both factors of the subscale demonstrated good internal consistency as determined by a Cronbach alpha of 0.74 for the measure of family support and 0.88 for the measure of relationship satisfaction for this study.

\section{Family Conflict and Distress}

The Family Conflict and Distress (FCD) subscale consists of the family module from the Addiction Severity Index, an evaluative and diagnostic instrument used to assess an individual's level of alcohol and drug abuse or dependency [27]. The three-item subscale was used to measure occurrence of family conflict in the last $30 \mathrm{~d}$, distress related to family conflict, and perceived need for family therapy [27]. Although the FCD subscale originated from the Addiction Severity Index, the FCD measures general family conflict; the instrument does not specify conflict regarding substance use or addiction.

\section{Statistical Analysis}

Data were analyzed with SPSS software (version 22.0, IBM; Armonk, New York). Pearson correlations were used to assess the bivariate relationships between the PANSS subscales and the perceived family relationship and functioning variables. In addition, multivariable analyses were conducted to assess the unique contribution of the PANSS subscales to perceived family variables. The PANSS subscales were log-transformed to improve normality; the transformed variables showed acceptable skew and kurtosis. A multiple linear regression model was used for the continuous family functioning variables (FAD subscales, FPSC subscales, and PFSS subscales), and a logistic regression model was used for the dichotomous family functioning variables (FCD variables). Age, race, sex, and marital status were added to the regression models as covariates.

\section{RESULTS}

\section{Description of Sample}

Table 1 shows the demographic characteristics and diagnoses of the sample, as well as mean scores on the PANSS subscales. Most study participants were male $(n=$ $190,84 \%)$. The mean \pm standard deviation age was $51.5 \pm$
Table 1.

Demographic and symptom characteristics of 226 outpatient Veterans diagnosed with serious mental illness.
Demographic Characteristic
n (\%) or
Mean \pm SD

\begin{tabular}{|c|c|}
\hline Age, yr & $51.5 \pm 9.1$ \\
\hline Education, yr & $13.4 \pm 2.1$ \\
\hline Number of Children & $1.7 \pm 1.8$ \\
\hline \multicolumn{2}{|l|}{ Sex } \\
\hline Male & $190(84)$ \\
\hline Female & $36(16)$ \\
\hline \multicolumn{2}{|l|}{ Marital Status } \\
\hline Not Married & $183(81)$ \\
\hline Married & $43(19)$ \\
\hline \multicolumn{2}{|l|}{ Race/Ethnicity } \\
\hline African American & $130(58)$ \\
\hline Caucasian & $82(36)$ \\
\hline Multiracial & $6(3)$ \\
\hline American Indian or Alaskan Native & $3(1)$ \\
\hline Asian & $2(<1)$ \\
\hline Pacific Islander & $1(<1)$ \\
\hline Not of Hispanic/Latino Origin & $217(96)$ \\
\hline Of Hispanic/Latino Origin & $8(4)$ \\
\hline \multicolumn{2}{|l|}{ Living Arrangements } \\
\hline Not Living with Family & $124(55)$ \\
\hline Living with Family & $99(44)$ \\
\hline \multicolumn{2}{|l|}{ Employment Status } \\
\hline Unemployed & $182(80)$ \\
\hline Employed (paying job) & $44(20)$ \\
\hline \multicolumn{2}{|l|}{ Diagnosis } \\
\hline Schizophrenia & $69(31)$ \\
\hline Schizoaffective Disorder & $30(13)$ \\
\hline Bipolar Disorder & $102(45)$ \\
\hline Depression with Psychotic Features & $16(7)$ \\
\hline Psychotic Disorder & $9(4)$ \\
\hline
\end{tabular}

Symptom Characteristic: PANSS Subscales*

$\begin{array}{ll}\text { Positive } & 8.1 \pm 4.1 \\ \text { Expression (negative) } & 6.1 \pm 2.8 \\ \text { Motivation and Pleasure (negative) } & 4.4 \pm 2.1 \\ \text { Disorganized } & 5.3 \pm 2.2 \\ \text { Excited } & 5.6 \pm 1.9 \\ \text { Depression } & 7.8 \pm 3.4\end{array}$

Note: $n=2$ did not report racial background, $n=1$ did not report ethnicity, $n=$ 3 did not report living arrangements.

*PANSS statistics reflect the original values before log-transformation, higher PANSS scores indicate greater symptom severity, and data reported as mean \pm standard error.

PANSS = Positive and Negative Syndrome Scale, $\mathrm{SD}=$ standard deviation 
9.1 yr. A total of $130(58 \%)$ participants were African American, $82(36 \%)$ were Caucasian, $12(5 \%)$ were of other races, and $2(<1 \%)$ did not report racial background.

\section{Bivariate Analyses}

Table 2 shows the correlation matrix between symptoms and family variables. The depression subscale was significantly related to each of the family functioning variables, and the disorganization subscale was not related to any. The relationship of the other PANSS subscales varied by the type of perceived family functioning.

Family Problem Solving, General Functioning, and Communication

Higher scores on the depressive, excited, and positive symptom PANSS subscales were significantly correlated with poorer patient-perceived problem solving and

Table 2.

Correlation between symptom measures and perceived family relationship measures. Items under PANSS, FAD, and FPSC are instrument subscales.

\begin{tabular}{|c|c|c|c|c|c|c|}
\hline \multirow[b]{2}{*}{ Measure } & \multicolumn{6}{|c|}{ PANSS Subscale* } \\
\hline & Positive & Expression & $\begin{array}{c}\text { Motiv./ } \\
\text { Pleasure }\end{array}$ & Disorganized & Excited & Depression \\
\hline \multicolumn{7}{|l|}{ PANSS* $^{*}$} \\
\hline Positive & 1 & - & - & - & - & - \\
\hline Expression & $0.245^{\dagger}$ & 1 & - & - & - & - \\
\hline Motiv./Pleasure & $0.302^{\dagger}$ & $0.431^{\dagger}$ & 1 & - & - & - \\
\hline Disorganized & $0.383^{\dagger}$ & $0.476^{\dagger}$ & $0.265^{\dagger}$ & 1 & - & - \\
\hline Excited & $0.270^{\dagger}$ & 0.025 & 0.130 & 0.154 & 1 & - \\
\hline Depression & $0.371^{\dagger}$ & 0.055 & $0.433^{\dagger}$ & 0.092 & $0.283^{\dagger}$ & 1 \\
\hline \multicolumn{7}{|l|}{ FAD $^{\S}$} \\
\hline General & $0.150^{+}$ & -0.049 & 0.113 & -0.012 & 0.130 & $0.240^{\dagger}$ \\
\hline Problem & 0.128 & -0.106 & 0.085 & 0.001 & $0.135^{\dagger}$ & $0.267^{\dagger}$ \\
\hline \multicolumn{7}{|l|}{ FPSC } \\
\hline Affirming & -0.167 & 0.091 & -0.122 & -0.017 & $-0.200^{\dagger}$ & $-0.289^{\dagger}$ \\
\hline Incendiary ${ }^{\S}$ & 0.160 & $-0.145^{\star}$ & 0.130 & 0.053 & $0.165^{t}$ & $0.288^{\dagger}$ \\
\hline Total $^{\Phi}$ & $-0.185^{\dagger}$ & 0.128 & -0.132 & -0.046 & $-0.194^{\dagger}$ & $-0.318^{\dagger}$ \\
\hline \multicolumn{7}{|l|}{ PFSS } \\
\hline Family Relationship/Support ${ }^{\Phi}$ & -0.100 & 0.027 & $-0.173^{\dagger}$ & -0.024 & -0.123 & $-0.208^{\dagger}$ \\
\hline Satisfaction with Family Relationship ${ }^{\Phi}$ & -0.133 & 0.091 & -0.106 & -0.031 & $-0.151^{\ddagger}$ & $-0.198^{\dagger}$ \\
\hline \multicolumn{7}{|l|}{ FCD } \\
\hline Serious Problems with Family in Past $30 \mathrm{~d}^{\S}$ & $0.168^{\dagger}$ & -0.083 & 0.030 & 0.026 & $0.171^{\dagger}$ & $0.306^{\dagger}$ \\
\hline $\begin{array}{l}\text { Very Troubled by Problems with Family } \\
\text { in Past } 30 \mathrm{~d}^{\S}\end{array}$ & 0.137 & -0.125 & 0.014 & -0.075 & $0.197^{\dagger}$ & $0.292^{\dagger}$ \\
\hline $\begin{array}{l}\text { Importance of Treatment/Counseling for } \\
\text { Family Problems }\end{array}$ & 0.008 & -0.104 & -0.014 & -0.067 & $0.140^{\ddagger}$ & $0.211^{\dagger}$ \\
\hline $\begin{array}{l}{ }^{*} \text { Higher PANSS scores indicate greater symptom ser } \\
\text { †Statistically significant at } p \leq 0.01 . \\
{ }^{\dagger} \text { Statistically significant at } p \leq 0.05 \text {. } \\
{ }^{\$} \text { Higher scores indicate poorer functioning/negative } \\
{ }_{\text {IHigher scores indicate better functioning/positive }} \\
{ }^{* *} \text { Higher scores indicate higher perception of import } \\
\text { FAD = Family Assessment Device, FCD = Family C } \\
\text { and Negative Syndrome Scale, PFSS = Perceived Fa }\end{array}$ & $\begin{array}{l}\text { erception. } \\
\text { ception. } \\
\text { ace. } \\
\text { hflict and Di } \\
\text { iily Support }\end{array}$ & $\begin{array}{l}\mathrm{PSC}=\text { Family } \\
\text { isfaction. }\end{array}$ & blem Solvi & ommunication, Mo & $=$ motivatio & ANSS $=$ Positive \\
\hline
\end{tabular}


communication. Higher scores on the expression subscalethe subset of negative symptoms that includes blunted affect, lack of spontaneity, and motor retardation - were significantly related to less incendiary communication.

\section{Perceived Family Support and Satisfaction}

In addition to the depression subscale, the excited subscale was significantly correlated with less satisfaction with family relationships, and the negative symptom subscale motivation and pleasure was significantly correlated with poorer perceived family support.

\section{Family Conflict and Distress}

Higher levels of depressive and excited symptoms were significantly correlated with greater perceived conflict, distress, and belief that treatment or counseling for family problems is important. Positive symptoms were also related to perceived conflict and distress but not belief that treatment or counseling is important.

\section{Multivariable Analyses}

Table 3 shows the unique influence of symptom variables on patient-perceived family variables.

\section{Family Problem Solving, General Functioning, and Communication}

Higher levels of depression uniquely contributed to poorer patient-perceived family problem solving as measured by the FAD as well as to lower levels of family communication. In addition, greater levels of expressive negative symptoms significantly, uniquely contributed to producing less incendiary communication, while greater levels of expressive negative symptoms uniquely contributed to better overall communication. Higher levels of disorganized symptoms also uniquely contributed to poorer communication as measured by the FPSC incendiary subscale.

Table 3.

Multiple regression results (models 1-7) and logistic regression results (models 8-10). Independent variables are subscales of the PANSS.

\begin{tabular}{|c|c|c|c|c|c|c|c|c|c|c|}
\hline $\begin{array}{l}\text { Independent } \\
\text { Variable }\end{array}$ & Model 1* & Model 2* & Model $3^{\dagger}$ & Model $4 *$ & Model $5^{\dagger}$ & Model $6^{\dagger}$ & Model $7^{\dagger}$ & Model 8* & Model 9* & Model 10 \\
\hline oefficient & $\beta$ & $\beta$ & $\beta$ & $\beta$ & $\beta$ & $\beta$ & $\beta$ & UN & ה & 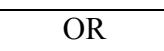 \\
\hline ositive $^{\S}$ & .105 & 0.042 & -0.064 & 0.068 & -0.079 & -0.055 & -0.074 & 1.752 & 1.734 & 0.770 \\
\hline ixpression ${ }^{\S}$ & -0.075 & -0.138 & 0.136 & $-0.255^{\mathbb{\Phi}}$ & $0.210^{\top}$ & 0.084 & 0.155 & 0.032 & 0.506 & 0.720 \\
\hline Motiv./Pleasure ${ }^{\S}$ & 0.052 & 0.039 & -0.058 & 0.094 & -0.072 & -0.130 & -0.087 & 0.542 & 0.586 & 0.634 \\
\hline isorganized ${ }^{\S}$ & -0.039 & 0.008 & -0.032 & $0.165^{* *}$ & -0.110 & -0.053 & -0.062 & & 8 & .885 \\
\hline Depression $^{\S}$ & 0.154 & $0.212^{\mathbb{9}}$ & $-0.199^{* *}$ & $0.160^{* *}$ & $-0.200^{9}$ & -0.076 & -0.090 & $3.630^{\natural}$ & $4.969^{\natural}$ & $3.451^{\text {ब }}$ \\
\hline Model & $F_{(10,208)}$ & $F_{(10,208)}$ & $F_{(10,204)}$ & $F_{(10,206)}$ & $F_{(10,206)}$ & $F_{(10,203)}$ & $F_{(10,210)}$ & $\chi^{2}(10)$ & $\chi^{2}(10)$ & $\chi^{2}(10)$ \\
\hline Statistic & 1.862 & $3.362^{\dagger \dagger}$ & $3.814^{\dagger \dagger}$ & $5.093^{\dagger \dagger}$ & $5.191^{\dagger \dagger}$ & $2.467^{\complement}$ & $2.300^{* *}$ & $43.897^{\dagger \dagger}$ & $33.236^{\dagger \dagger}$ & $19.610^{* *}$ \\
\hline $\mathrm{R}^{2}$ & 0.082 & 0.139 & 0.157 & 0.198 & 0.201 & 0.108 & 0.099 & - & - & - \\
\hline \multicolumn{11}{|c|}{ 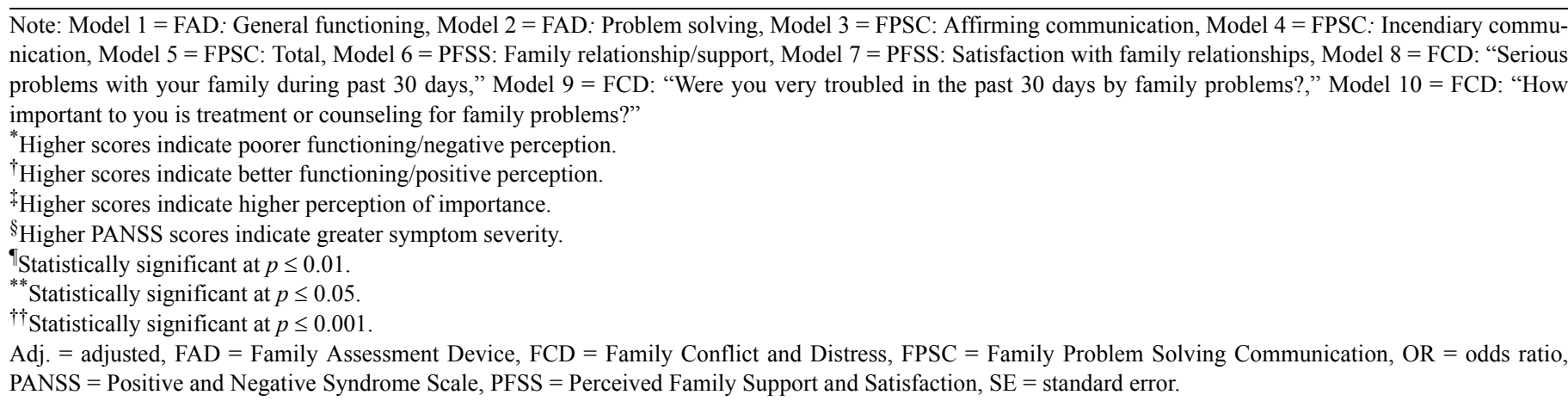 } \\
\hline
\end{tabular}




\section{Perceived Family Support and Satisfaction}

There were no unique contributions of symptoms to perceptions of family support and relationship satisfaction, despite several significant bivariate relationships.

\section{Family Conflict and Distress}

Greater depression uniquely contributed to greater perceived conflict, distress, and belief that treatment or counseling for family problems is important. No other symptom measures uniquely influenced perceptions of family relationships.

\section{DISCUSSION}

This study explored whether patient symptoms, including depressive and psychotic, uniquely influenced perceptions of family relationships, including general functioning, problem solving, communication, support, relationship satisfaction, conflict, and distress. As predicted, more severe depressive symptomology uniquely contributed to the prediction of poorer family functioning and greater conflict and distress. These results are consistent with previous work that suggests that greater depression severity and poorer recovery correlate with lower patient-perceived family functioning and support [8-10]. While we cannot assert causation from this study, the association between depression and more problematic perceptions of family relationships suggests the possibility of a negative effect of depression on family relationships, even among patients with psychotic disorders. Such depressive symptoms can be overlooked in the context of psychosis, but this relationship (depression and perceived poor family relationship) may be an unidentified but critical barrier to involving families in the care of these individuals. Depression may also have a direct effect on the nature of the family communication, inhibiting problem solving and causing distress. These results suggest there may be a benefit to prioritizing patients experiencing concurrent psychosis and depression for more careful evaluation of the need for family work. Clinicians working with these patients may need to probe carefully to determine the extent to which depression is coloring efforts to work with the patients' families. A critical question is whether the patients' perceptions are driven by depression such that treating the depression will improve perceived family problems, communication, and problem solving.

Another confounding variable is family members' burden and the effects that it might have on their attitude and behavior. Although our data are limited to patients' selfreports, Coyne et al. studied the effects on family members of living with a depressed person [28]; they showed that a measure of family members' emotional reactions to patients' symptoms was a significant independent predictor of the differences of distress between family members living with someone currently in a depressive episode versus someone not experiencing a depressive episode. Further isolated analysis on this measure of subjective burden showed that high rates of family member distress were reduced to almost nothing when controlling for the burden [28]. It is possible that patients' depressive symptoms and their families' way of reacting to these symptoms have a negative and cyclical effect on each other.

It is also important to consider the possibility that depressed individuals, compared with other psychiatric groups, may be more susceptible to family conflict and problematic communication; this hypothesis is consistent with the seminal findings of Vaughn and Leff [29], showing that lower levels of expressed emotion predicted relapse in a sample diagnosed with depression compared with schizophrenia. While we do not have independent data collected from family members here, our pattern of results makes it even more important that clinicians work with families. The fact that depression is uniquely associated with an increased belief that family counseling is important will help support that effort. Whatever the causal pathways are in the relationship between depression and troubled family relationships, these data underscore the importance of addressing depression among individuals with psychotic disorders in order to support increased family participation in care and family functioning.

In contrast to depression, the absence of emotional tone in the form of blunted affect and lack of spontaneity (negative symptoms) uniquely contributed to more favorably reported family relationships. The observed difference in results between expressive symptoms and motivation and pleasure symptoms supports the validity of dividing negative symptoms into categories [20-21]. This could very well be a reflection of an overall dampening of distress and negative affect among those with greater levels of expressive symptoms. Individuals with high levels of expressive symptoms perceived less incendiary communication. Their own constrained behaviors may evoke less conflict. Alternatively, individuals with higher levels of expressive symptoms could reflect lack of awareness or sensitivity to emotional conflict and difficulty perceiving and understanding emotions in others. Unlike expressive symptoms, 
disorganization was associated with poorer communication and more perceived incendiary communication. It is plausible that disorganized behavior might frustrate families and evoke negative responses. Such reactions might reinforce disorganized symptoms, similar to depressive symptoms, and cause both family relationships and symptoms to negatively affect each other in a cyclical fashion. If so, it would be important for families to learn how to deal with such behavior without lashing out. Of course, this study does not allow us to know actual family behavior, but it makes sense that more disorganization might be more difficult for families. In any event, when attempting to include families in care and improve family well-being, the importance of the client's behavioral disorganization should not be overlooked.

It is notable that positive symptoms did not uniquely contribute to patients' perceptions of family relationships. Perhaps perceptions of family relationships are largely driven by variation in emotional and affective tone and less affected by delusions and hallucinations, particularly if those symptoms do not have any family-related content. Interestingly, no constellation of symptoms independently contributed to perceived family support or satisfaction with family relationships, although some symptom variables did have a significant association with these family variables in the bivariate analyses and symptoms as a whole significantly predicted perceived family support and satisfaction in the overall regression model analyses. This pattern of results suggests that perceived family support and satisfaction are more "global" evaluations that reflect, in part, an overall symptom profile rather than specific symptom levels; likely many other variables not captured here (e.g., financial assistance and help with activities of daily living from relatives) also influence perception of family support and satisfaction.

This study is limited by our use of cross-sectional data, which precludes making inferences about causality. Further, the sample is restricted to the VA, is largely male, and only includes individuals whose families did not have regular contact with clinicians. Although this VA sample may not be representative of the general population with SMI, research comparing long-stay male psychiatric patients at VA facilities $(N=54)$ versus state psychiatric facilities $(N=75)$ shows that for both groups, cognitive impairments and negative symptoms predicted adaptive deficits while these deficits were unassociated with positive psychotic symptoms [30]. This study's largely male sample and Harvey et al.'s [30] full male sample empha- size the need for further research to identify the generalizability of these results in female Veteran and non-Veteran samples. Although females made up only 16 percent of our study sample, this proportion is higher than that found in the 2007 Veterans Health Administration evaluation of almost 900,000 Veterans with SMI, which reported 6.7 percent total female Veterans [31]. In the general population, younger individuals with SMI $(\leq 31 \mathrm{yr})$ are more likely to receive treatment and have higher rates of care than older individuals with SMI ( $\geq 64 \mathrm{yr}$ ) [31]. In the Veteran population, the opposite trend has been observed. In the analysis by Watkins et al. [31], approximately 40 percent of Veterans receiving services for SMI were between the ages of 55 and $64 \mathrm{yr}$, and the smallest cohorts receiving services were between 18 and $34 \mathrm{yr}$, followed by those 35 to 44 yr. Though the findings of this study are highly relevant to the Veteran population, particularly older Veterans, symptoms may have different effects on patients' perceptions of family relationships in the non-Veteran SMI population and in younger individuals with SMIboth Veteran and non-Veteran. These weaknesses are mitigated by the size and diversity of the sample as well as the use of multiple dimensions of perceived family functioning and relationships and interviewer-based symptom ratings.

\section{CONCLUSIONS}

This study found that specific symptoms contributed unique variance in patients' reports of family support and functioning. Depression contributed unique variance to lower levels of family functioning and family communication as well as to higher levels of family conflict and distress. In contrast, the negative symptoms of reduced expression contributed unique variance to better communication, while positive symptoms had no effect on any family measure. While these findings do not permit inferences about causal pathways underlying these associations, they underscore the important role of depression and expressive negative symptoms in adopting a familycentered approach in the care of persons with SMI.

\section{ACKNOWLEDGMENTS}

\section{Author Contributions:}

Study concept and design: A. N. Cohen, A. Drapalski, D. Medoff, L. B. Dixon, S. M. Glynn. 
Acquisition of data: A. N. Cohen, A. Drapalski, D. Medoff, L. B. Dixon, S. M. Glynn.

Analysis and interpretation of data: A. N. Cohen, A. Drapalski, D. Medoff, L. B. Dixon, M. Haselden, S. M. Glynn, S. Piscitelli.

Drafting of manuscript: L. B. Dixon, M. Haselden, S. Piscitelli. Critical revision of manuscript for important intellectual content: A. N. Cohen, A. Drapalski, D. Medoff, L. B. Dixon, M. Haselden, S. M. Glynn, S. Piscitelli.

Statistical analysis: D. Medoff, L. B. Dixon, M. Haselden, S. Piscitelli. Obtained funding: A. N. Cohen, A. Drapalski, D. Medoff, L. B. Dixon, S. M. Glynn.

Financial Disclosures: The authors have declared that no competing interests exist.

Funding/Support: This material was based on work supported by VA Health Services Research and Development (award IIR 04-255) (Dr. Dixon). This research was also supported by the Mental Illness, Research, Education, and Clinical Center (MIRECC) of the VA Capitol Health Care Network and the MIRECC of the VA Desert Pacific Healthcare Network.

Institutional Review: The study protocol was approved by the University of Maryland School of Medicine Institutional Review Board and the VA Greater Los Angeles Healthcare System Institutional Review Board. Written informed consent was obtained from all participants before data collection.

Participant Follow-Up: The authors do not plan to notify study participants of the publication of this article.

\section{REFERENCES}

1. Bolkan CR, Bonner LM, Campbell DG, Lanto A, Zivin K, Chaney E, Rubenstein LV. Family involvement, medication adherence, and depression outcomes among patients in veterans affairs primary care. Psychiatr Serv. 2013;64(5):472-78. [PMID:23370463] http://dx.doi.org/10.1176/appi.ps.201200160

2. McFarlane WR, Dixon L, Lukens E, Lucksted A. Family psychoeducation and schizophrenia: A review of the literature. J Marital Fam Ther. 2003;29(2):223-45. [PMID:12728780] http://dx.doi.org/10.1111/j.1752-0606.2003.tb01202.x

3. Pitschel-Walz G, Leucht S, Bäuml J, Kissling W, Engel RR. The effect of family interventions on relapse and rehospitalization in schizophrenia-A meta-analysis. Schizophr Bull. 2001;27(1):73-92. [PMID:11215551] http://dx.doi.org/10.1093/oxfordjournals.schbul.a006861

4. Pharoah F, Mari J, Rathbone J, Wong W. Family intervention for schizophrenia. Cochrane Database Syst Rev. 2010; (12):CD000088. [PMID:21154340] http://dx.doi.org/10.1002/14651858.CD000088.pub3

5. Randolph ET, Eth S, Glynn SM, Paz GG, Leong GB, Shaner AL, Strachan A, Van Vort W, Escobar JI, Liberman RP. Behavioural family management in schizophrenia. Outcome of a clinic-based intervention. Br J Psychiatry. 1994;
164(4):501-6. [PMID:8038939]

http://dx.doi.org/10.1192/bjp.164.4.501

6. Cohen AN, Glynn SM, Murray-Swank AB, Barrio C, Fischer EP, McCutcheon SJ, Perlick DA, Rotondi AJ, Sayers SL, Sherman MD, Dixon LB. The family forum: Directions for the implementation of family psychoeducation for severe mental illness. Psychiatr Serv. 2008;59(1):40-48. [PMID:18182538] http://dx.doi.org/10.1176/ps.2008.59.1.40

7. Drapalski A, Leith J, Dixon LB. Involving families in the care of persons with schizophrenia and other serious mental illnesses: History, evidence, and recommendations. Clin Schizophr Relat Psychoses. 2009;3(1):39-49.

http://dx.doi.org/10.3371/CSRP.3.1.4

8. Febres J, Rossi R, Gaudiano BA, Miller IW. Differential relationship between depression severity and patients' perceived family functioning in women versus in men. J Nerv Ment Dis. 2011;199(7):449-53. [PMID:21716057] http://dx.doi.org/10.1097/NMD.0b013e318221412a

9. Kamen C, Cosgrove V, McKellar J, Cronkite R, Moos R. Family support and depressive symptoms: A 23-year followup. J Clin Psychol. 2011;67(3):215-23. [PMID:21254050] http://dx.doi.org/10.1002/jclp.20765

10. Keitner GI, Ryan CE, Miller IW, Norman WH. Recovery and major depression: Factors associated with twelvemonth outcome. Am J Psychiatry. 1992;149(1):93-99.

[PMID:1728193]

http://dx.doi.org/10.1176/ajp.149.1.93

11. Lincoln KD, Chatters LM, Taylor RJ. Social support, traumatic events, and depressive symptoms among African Americans. J Marriage Fam. 2005;67(3):754-66. [PMID:16429592] http://dx.doi.org/10.1111/j.1741-3737.2005.00167.x

12. Onwumere J, Kuipers E, Bebbington P, Dunn G, Freeman D, Fowler D, Garety P. Patient perceptions of caregiver criticism in psychosis: Links with patient and caregiver functioning. J Nerv Ment Dis. 2009;197(2):85-91.

[PMID:19214042]

http://dx.doi.org/10.1097/NMD.0b013e3181960e57

13. Tomlinson E, Onwumere J, Kuipers E. Distress and negative experiences of the caregiving relationship in early psychosis: Does social cognition play a role? Early Interv Psychiatry. 2014;8(3):253-60. [PMID:23489370] http://dx.doi.org/10.1111/eip.12040

14. Cohen AN, Drapalski AL, Glynn SM, Medoff D, Fang LJ, Dixon LB. Preferences for family involvement in care among consumers with serious mental illness. Psychiatr Serv. 2013;64(3):257-63. [PMID:23242515] http://dx.doi.org/10.1176/appi.ps.201200176

15. Dixon LB, Glynn SM, Cohen AN, Drapalski AL, Medoff D, Fang LJ, Potts W, Gioia D. Outcomes of a brief program, REORDER, to promote consumer recovery and family involvement in care. Psychiatr Serv. 2014;65(1):116-20. 


\section{[PMID:24177229]}

http://dx.doi.org/10.1176/appi.ps.201300074

16. Gioia D, Autrey S, Drapalski AL, Glynn S, Cohen AN, Dixon LB. Veterans' views of a shared decision-making process: A qualitative substudy of REORDER. Am J Psychiatr Rehabil. 2014;17(4):348-64.

http://dx.doi.org/10.1080/15487768.2014.903877

17. Kay SR, Fiszbein A, Opler LA. The Positive and Negative Syndrome Scale (PANSS) for schizophrenia. Schizophr Bull. 1987;13(2):261-76. [PMID:3616518] http://dx.doi.org/10.1093/schbul/13.2.261

18. Stefanovics EA, Elkis H, Zhening L, Zhang XY, Rosenheck RA. A cross-national factor analytic comparison of three models of PANSS symptoms in schizophrenia. Psychiatry Res. 2014;219(2):283-89. [PMID:24930581] http://dx.doi.org/10.1016/j.psychres.2014.04.041

19. Wallwork RS, Fortgang R, Hashimoto R, Weinberger DR, Dickinson D. Searching for a consensus five-factor model of the Positive and Negative Syndrome Scale for schizophrenia. Schizophr Res. 2012;137(1-3):246-50.

[PMID:22356801] http://dx.doi.org/10.1016/j.schres.2012.01.031

20. Horan WP, Kring AM, Gur RE, Reise SP, Blanchard JJ. Development and psychometric validation of the Clinical Assessment Interview for Negative Symptoms (CAINS). Schizophr Res. 2011;132(2-3):140-45. [PMID:21798716] http://dx.doi.org/10.1016/j.schres.2011.06.030

21. Kring AM, Gur RE, Blanchard JJ, Horan WP, Reise SP. The Clinical Assessment Interview for Negative Symptoms (CAINS): Final development and validation. Am J Psychiatry. 2013;170(2):165-72. [PMID:23377637] http://dx.doi.org/10.1176/appi.ajp.2012.12010109

22. Epstein NB, Baldwin LM, Bishop DS. The McMaster Family Assessment Device. J Marital Fam Ther. 1983;9(2): 171-80. http://dx.doi.org/10.1111/j.1752-0606.1983.tb01497.x

23. Corcoran K, Fischer J. Measures for clinical practice and research. Couples, families and children. 5th ed. Vol 1. New York (NY): Oxford University Press; 2013.

24. McCubbin MA, McCubbin HI, Thompson AI. Family assessment: Resiliency, coping and adaptation-inventories for research and practice. Instrument-Family Problem Solving Communication (FPSC). Madison (WI): University of Wisconsin; 1996.

25. Uttaro T, Mechanic D; National Alliance for the Mentally Ill. The NAMI consumer survey analysis of unmet needs. Hosp Community Psychiatry. 1994;45(4):372-74. [PMID:8020925]

26. Murray-Swank A, Glynn S, Cohen AN, Sherman M, Medoff DP, Fang LJ, Drapalski A, Dixon LB. Family con- tact, experience of family relationships, and views about family involvement in treatment among VA consumers with serious mental illness. J Rehabil Res Dev. 2007;44(6): 801-11. [PMID:18075938] http://dx.doi.org/10.1682/JRRD.2006.08.0092

27. McLellan AT. Guide to the Addiction Severity Index: Background, administration, and field testing results. Rockville (MD): National Institute on Drug Abuse; 1985.

28. Coyne JC, Kessler RC, Tal M, Turnbull J, Wortman CB, Greden JF. Living with a depressed person. J Consult Clin Psychol. 1987;55(3):347-52. [PMID:3597947] http://dx.doi.org/10.1037/0022-006X.55.3.347

29. Vaughn CE, Leff JP. The influence of family and social factors on the course of psychiatric illness. A comparison of schizophrenic and depressed neurotic patients. Br J Psychiatry. 1976;129(2):125-37. [PMID:963348]

http://dx.doi.org/10.1192/bjp.129.2.125

30. Harvey PD, Jacobsen H, Mancini D, Parrella M, White L, Haroutunian V, Davis KL. Clinical, cognitive and functional characteristics of long-stay patients with schizophrenia: A comparison of VA and state hospital patients. Schizophr Res. 2000;43(1):3-9. [PMID:10828410] http://dx.doi.org/10.1016/S0920-9964(99)00182-6

31. Watkins KE, Smith B, Paddock SM, Mannle TE, Woodroffe A, Solomon J, Sorbero ME, Farmer CM, Hepner KA, Adamson DM, Forrest L, Call C, Pincus HA. Program evaluation of VHA mental health services: Capstone report. Technical report by Altarum Institute and RAND Health. Sponsored by the U.S. Department of Veterans Affairs [Internet]. Santa Monica (CA): RAND Corporation; 2011. 198 p. Available from:

http://www.mentalhealth.va.gov/docs/

capstone revised TR956 compiled.pdf

Submitted for publication August 19, 2015. Accepted in revised form November 13, 2015.

This article and any supplementary material should be cited as follows:

Haselden M, Piscitelli S, Drapalski A, Medoff D, Glynn SM, Cohen AN, Dixon LB. Relationship between symptoms and family relationships in Veterans with serious mental illness. J Rehabil Res Dev. 2016;53(6):743-52. http://dx.doi.org/10.1682/JRRD.2015.08.0158

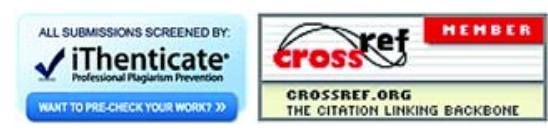

